added to ammonia, which stimulates the local circulation, forms the best inhalant for the prevention of the disease I yet know of. It may be used as a spray, or as a perfume to be used two or three times a day, inhaled by means of a handkerchief. I think it vastly superior to menthol. I cannot speak too highly of menthol injected into the nostril with olive oil in chronic catarrh, but its effect as an inhalant has not been altogether free from bad effects.

Curative treatment.-The idea of killing the germ when it is once in the blood is out of the question. We must remember the germ first attacks the nasal passages and travels towards the bronchi, and is favoured by a concested surface. Therefore, if we can limit this surface, we limit the area of absorption; and I am convinced this is best done by diaphoretics, which at the same time reduce the temperature. When the temperature is normal, the symptoms of prostration are best treated with strychnine and stimulants. I believe the disease is on the increase in the west of London. It first of all attacks large institutions, where people are congregated together in large numbers, but it is slower in permeating into private families. It is comforting that its consequences as a rule are not serious. Stanwick-road, West Kensington, W.

\section{COLOTOMY AT SEVENTY-THREE YEARS OF AGE ; PATIENT SURVIVING THREE YEARS LATER.}

\section{BY GEORGE A. HAWKINS-AMBLER, M.R.C.S. \&c.}

THERE is nothing in the following case to warrant me in intruding it upon readers of THE LANCET beyond the circumstances under which the operation was performed, and the immense gain to the patient in life and ease from its perforniance. The facts that the operating room was a small and ill-lighted cottage bedroom, the patient at an advanced time of life, and her nurses two daughters completely uninstructed in that art, have induced me to think the case of sufficient interest to be recorded as an encouragement to some who, like myself, often feel an aversion to operate under the unfavourable conditions imposed upon them by country life and the exigencies of practice amongst the working classes.

Mrs. B _ tailoress, aged seventy-three years, had in January, 1887, been under my care for several months, during which her symptoms were those of growing obstruction of the bowels from a cancerous growth that could be felt constricting the rectum within reach of the finger. Frequent calls to stool, with straining, griping, and the passage of scanty, dark, or black stools, evidently the washings of retained frees, had caused her much anxiety and a growing weakness. Drugs afforded but little relief, and that obtained from injections of warm water, oil, \&c., beyond the stricture by means of a catheter was only temporary and partial. The symptoms culminated by the end of the month in complete obstruction, incessant vomiting, tenesmus, and some tympanites, and became so rapidly grave that $I$ insisted upon what I had often urged previously - the performance of left lumbar colotomy. This I did on Jan. 29th, on which occasion Drs. Clark and Scougal of Huddersfield afforded me very valuable assistance. The operation calls for no detailed description, being perfectly simple and straightforward throughout; the gut was easily found, stitched to the margins of the wound, and opened at once. I should have remarked that the patient was stout and of a full habit, and there was a thick layer of fat to cut through. The patient was very restless on recovering from the effects of the ether, and her temperature ran up to $100^{\circ} \mathrm{F}$. in the evening, while for some days the pulse hovered about 120 . The tongue was dry and caked, and my impromptu nurses varied the monotony of the veal broth, soda water and milk, \&c. I had ordered by tea and toast and more substantial nourish. ment, and admitted the patient's friends to converse and sympathise with her, which they came to do "early and often." We now had the usual exhausting discharge of long-retained freces to contend with, and I dressed the wound myself three times a day, took care that the patient was duly supplied with food, port wine, and champagne, and relieved her pain with opium. There was and has since been occasional trouble with the urine, it being scanty and deep-coloured. There was, too, much inflammation round the margins of the wound, and on Feb. 4th I noted a pulse of 140, much pain and exhaustion, and difficult and painful passage of hard, clay-like freces, which were scooped out of the gaping wound, the temperature reached $100^{\circ} 4^{\circ}$. After this, on Feb. 5th, the motions became very liquid and copious; but the patient took nourishment freely, and I gave her malt extract and syrup of hyposphosphites. By March 19th she was sitting up four hours a day, and on June 16th made a complete pair of trousers, for which she used the sewing machine, and went about her work as usual, suffering no inconvenience beyond occasional bulging of the intestine through the wound, and sometimes a slight sanious discharge. from the rectum. Shehaslostall the straining and griping and frequent stools, and one day during the last summer walked more than four miles, up and down hill, withoutspecial fatigue. As to the cancerous growth, that makes slow but certain progress, and the patient is losing ground, developing cachexia, and growing less active. She is at work yet, but does little, and has an attack at intervals, growing less prolonged, of one or two months, of partial suppression of urine, pain in the umbilical region, watery and clayey motions, and (but only at such times) troublesome bulging of the bowel through the wound. During the attack from which she has just recovered there was a slight discharge of blood from the rectum.

I have aimed in these brief notes at telling merely the salient points of this case, and avoiding such detail and description as was likely to be tedious and unprofitable; but $I$ trust that my endeavour to show the encouraging features in it will not be altogether without success.

Firkburton, Huddersfield.

\section{PATHOLOGICAL OBJECTIONS TO CURETTING} THE UTERUS IN PUERPERAL FEVER.

\section{BY E. TENISON COLLINS, L.S.A.}

A RECENT SUGGESTION to curette the uterus in puerperal fever appears both unnecessary and pathologically un. justifiable. This fever is a septicæmia, in no way specific or different from general wound sepsis, and may be said to occur as sapremia or as septic infection.

In the sapræmic form the putrefactive germs admitted into the genital tract during labour rapidly multiply in the lochial discharges (themselves innocuous) and in the contused or abraded mucous surfaces. These special germs of putrefaction are saprophytic and speedily perish in the blood, and are powerless to attack living tissues. The discharges become offensive, and if partially retained give. rise to constitutional symptoms. It is, however, only the chemical products and not the organisms themselves that invade the system and cause the sapræmic form of puerperal fever, the intensity of which is directly proportionate to the dose of chemical poison absorbed. If the dose be a large one, the most severe symptoms of acute septic poisoning may set in and rapidly culminate in death. Certain post-mortem appearances are found, but no micro-organisms have been discovered in the blood, and the blood is not infective. The onset of the fever is indicated by a more or less rapid rise of temperature. There is usually no rigor, and the disease is non-infective. The obvious treatment is to remove the putrefactive material supplying the poison, and this can be done efficiently by intra-uterine antiseptic irrigation, inasmuch as the bacteria do not exist in the living uterine tissues. Curetting alone is useless, and if with irrigation unnecessary ; and further, by creating a fresh breach of surface for absorption, may be an actual source of danger. Curetting can only be of service for the removal of portions of putrefying placenta or decidua.

In the second form, or septic infection, micro-organisms again play an active part, but are pathogenic. They invade the living tissue and increase in the blood, causing fever of a well-known intensely contagious type. The nature of the virus is unknown, and though micrococci and streptococci have been found in all the organs secondarily affected by puerperal fever, they do not exist as a separate species like the tubercle bacillus or bacillus subtilis. The germs are introduced into the genital tract by the surgeon's hands or 